\title{
Correction to: A generalized Anderson-Darling test for the goodness-of-fit evaluation of the fracture strain distribution of acrylic glass
}

\author{
Marcel Berlinger ${ }^{1} \cdot$ Stefan Kolling ${ }^{1} \cdot$ Jens Schneider ${ }^{2}$ \\ Published online: 3 May 2021 \\ (c) The Author(s) 2021 \\ Correction to: \\ Glass Struct Eng \\ https://doi.org/10.1007/s40940-021-00149-7
}

The original version of this article unfortunately contained a typesetting mistake in two references. The corrected references are given below. The original article has been corrected.

Brokmann, C., Berlinger, M., Schrader, P., Kolling, S.: Fractographic fracture stress analysis of acrylic glass. ce/papers 3(1), 225-237 (2019).

Ensslen, F., Müller-Braun, S.: Study on edge strength of float glass as a function of relevant cutting process parameters. ce/papers 1(1), 189-202 (2017).

The original article can be found online at https://doi.org/10.1007/ s40940-021-00149-7.

$\triangle$ Marcel Berlinger

marcel.berlinger@me.thm.de

1 Institute of Mechanics and Materials, Technische Hochschule Mittelhessen - University of Applied Sciences, Wiesenstrasse 14, D-35390 Giessen, Germany

2 Institute of Structural Mechanics and Design, Technical University of Darmstadt, Franziska-Braun-Strasse 3, D-64287 Darmstadt, Germany
Open Access This article is distributed under the terms of the Creative Commons Attribution 4.0 International License (http://creativecomm ons.org/licenses/by/4.0/), which permits unrestricted use, distribution, and reproduction in any medium, provided you give appropriate credit to the original author(s) and the source, provide a link to the Creative Commons license, and indicate if changes were made.

Publisher's Note Springer Nature remains neutral with regard to jurisdictional claims in published maps and institutional affiliations. 